\title{
MECHANISM OF RELAXANT ACTION OF PAPAVERINE. EFFECT ON CAFFEINE-INDUCED CONTRACTION OF GUINEA PIG TAENIA COLI
}

\author{
Nobuyoshi SUNAGANE, Tsutomu URUNO and Kazuhiko KUBOTA \\ Department of Pharmacology. Fuculty of Pharmaceutical Sciences, \\ Science University of Tokyo, Shinjuku-ku, Tokyo 162, Japan
}

Accepted April 28, 1982

\begin{abstract}
The mode of action of papaverine on smooth muscle relaxation was examined through analyzing its effects on caffeine-induced contraction of guinea pig taenia coli, which might be due to calcium ion mobilized from intracellular store sites. Caffeine contraction induced in normal solution at $32{ }^{\circ} \mathrm{C}$ was decreased in the presence of papaverine but increased after the removal of papaverine. and it was also increased when the muscle was preincubated with papaverine and then washed out. These papaverine actions were inhibited at low temperature. Caffeine contraction induced in Ca-free, depolarizing solution was also enhanced by treatment with papaverine during $\mathrm{Ca}$-loading. Cyclic AMP and its dibutyryl derivative produced a similar effect on the caffeine contraction induced in normal or Ca-free. depolarizing solution as those of papaverine. In addition, a good correlation was observed between the papaverine-induced increases in caffeine response and in tissue cyclic AMP level. From these results, it is considered that papaverine increases cyclic AMP of the taenia coli, and this increased cyclic AMP stimulates accumulation of calcium ion into its storage sites from where calcium ion was released by caffeine, finally leading to smooth muscle relaxation.
\end{abstract}

A number of attempts have been made in order to elucidate the mechanisms of smooth muscle relaxation induced by papaverine. Effects of papaverine on the calcium movement of smooth muscle have been extensively studied $(1-5)$ because muscle relaxation is generally accepted to be initiated by decreasing cytoplasmic calcium ion levels of the muscle cells (6). Recent investigations have shown that the calcium uptake of the microsomal fraction isolated from smooth muscle cells is accelerated by papaverine (1-3). Since the acceleration of microsomal calcium uptake will lead to an increase in sequestration of cytoplasmic calcium ion to intracellular storage sites, the effect of papaverine on the calcium uptake of the microsomal fraction may cause smooth muscle relaxation. However, direct evidence that the action of papaverine on the calcium sequestration contributes to muscle relaxation in intact smooth muscle cells has not been provided.

Caffeine has been demonstrated to induce contraction of guinea pig taenia coli by releasing calcium ions from its intracellular binding sites $(7,8)$. In our present work, we aimed to explore the mode of action of papaverine through analyzing its effects on the caffeine-induced contraction of guinea- 
pig taenia coli.

\section{MATERIALS AND METHODS}

Male guinea pigs weighing 300 to $450 \mathrm{~g}$ were killed by a blow on the head, and the taenia coli was isolated from the colon. The strip of taenia coli was placed in a $10 \mathrm{ml}$ organ bath filled with a bathing solution which was kept at selected temperatures $\left(12^{\circ}\right.$. $27^{\circ}$ and $32^{\circ} \mathrm{C}$ ) and bubbled with air. The compositions of the bathing solutions used were as follows (in $\mathrm{mM}$ ): Locke-Ringer solution (normal solution) consisted of $\mathrm{NaCl}$. 154: $\mathrm{KCl}$, 5.6: $\mathrm{CaCl}_{2}$, 2.2: $\mathrm{MgCl}_{2}, 2.1$; $\mathrm{NaHCO}_{3}, 5.9$; and glucose, 2.8. For Ca-free $\mathrm{K}$-rich Locke-Ringer solution (Ca-free $\mathrm{K}$ solution), $\mathrm{NaCl}$ and $\mathrm{NaHCO}_{3}$ were replaced with isosmolar $\mathrm{KCl}$ and $\mathrm{KHCO}_{3}$, respectively. and $\mathrm{CaCl}_{2}$ was omitted. The bathing solutions were changed every 5 min unless otherwise noted. The response of the taenia coli was recorded isotonically on a smoked drum by means of a lever loaded with $0.5 \mathrm{~g}$.

After the taenia coli was equilibrated for $1 \mathrm{hr}$ in normal solution kept at a given temperature, $5 \mathrm{mM}$ caffeine was repeatedly applied at intervals of $30 \mathrm{~min}$ until the caffeine-induced response became constant. and the following experiments were then performed.

1. Effects of papaverine on caffeine response in normal solution: The taenia coli equilibrated in normal solution at $12^{\circ} \mathrm{C}$ or $32^{\circ} \mathrm{C}$ was treated with papaverine in two different procedures. In the first procedure, the taenia coli was treated with papaverine for $5 \mathrm{~min}$, and then applied with $5 \mathrm{mM}$ caffeine in the presence of papaverine. The second procedure was as follows: the taenia coli was preincubated with papaverine for $10 \mathrm{~min}$ and washed out with the normal solution. Ten min after the washout. $5 \mathrm{mM}$ caffeine was applied. Caffeine responses of the taenia coli before and after these treatments with papaverine were compared.
2. Effects of cyclic AMP and dibutyryl cyclic AMP on caffeine response in normal solution: The taenia coli equilibrated in normal solution at $32^{\circ} \mathrm{C}$ was preincubated with cyclic AMP or dibutyryl cyclic AMP for $10 \mathrm{~min}$, washed with the normal solution for $10 \mathrm{~min}$. and then applied with $5 \mathrm{mM}$ caffeine. In some experiments, cyclic AMP was accompanied by a concomitant application of papaverine.

3. Effects of papaverine, cyclic AMP, and dibutyryl cyclic AMP on caffeine response in Ca-free K-solution: The taenia coli equilibrated in normal solution at $27^{\circ} \mathrm{C}$ was exposed to $\mathrm{Ca}$-free $\mathrm{K}$-solution, allowed to stand in this solution for $10 \mathrm{~min}$, and then applied with $5 \mathrm{mM}$ caffeine. This caffeineinduced contraction was taken as the standard response. After resting the muscle in the Ca-free K-solution for $15 \mathrm{~min}$, the taenia coli was treated with $1 \mathrm{mM} \mathrm{CaCl}_{2}$ for $10 \mathrm{~min}$ and subsequently washed with the Ca-free $\mathrm{K}$-solution for $10 \mathrm{~min}$ ( $\mathrm{Ca}$-loading process). Then, $5 \mathrm{mM}$ caffeine was applied to the muscle. The $\mathrm{Ca}$-loading was repeated 3 times at intervals of $30 \mathrm{~min}$. At the second Ca-loading process, the taenia coli was incubated with or without papaverine, cyclic AMP, or dibutyryl cyclic AMP during the treatment with $\mathrm{CaCl}_{2}$.

4. Effects of papaverine on tissue cyclic AMP level in $\mathrm{Ca}$-free $\mathrm{K}$-solution: The taenia coli loaded with $\mathrm{CaCl}_{2}$ as described above and applied with papaverine was frozen by immersing it in liquid nitrogen. Tissue concentrations of cyclic AMP were determined by the method of Gilman (9) using a test kit for determination of cyclic AMP (Boehringer Mannheim GmbH·Biochemica). The radioactivity was counted with an Aloka liquid scintillation counter (model LSC 670) in toluene scintillator. For these experiments. paired strips of the taenia coli isolated from one caecum were used. 


\section{RESULTS}

1. Effects of papaverine on caffeine response in normal solution: Application of $5 \mathrm{mM}$ caffeine to the taenia coli bathed in normal solution kept at $32^{\circ} \mathrm{C}$ elicited a phasic contraction of the muscle. When caffeine was applied to the taenia coli in the presence of papaverine, the caffeine-induced contraction was decreased. On the other hand, the caffeine contraction induced after the removal of papaverine by washing the muscle for $30 \mathrm{~min}$ was increased as compared to that obtained before the treatment with papaverine as shown in Fig. 1. Increasing effect of papaverine on the caffeine-induced con-
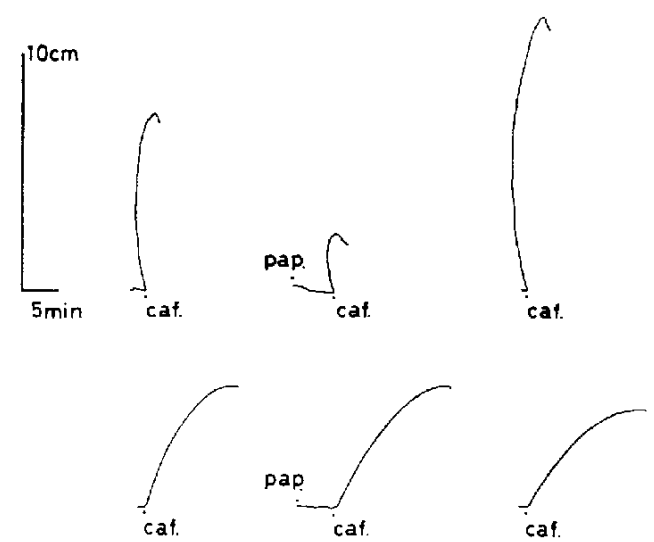

Fig. 1. Responses of the taenia coli to $5 \mathrm{mM}$ caffeine at $32^{\circ} \mathrm{C}$ (upper part) and $12^{\circ} \mathrm{C}$ (lower part). Caffeine was applied to the muscle in the presence of $6 \times 10^{-5} \mathrm{M}$ papaverine (middle trace) and 30 min after washing out of papaverine (right trace). Left trace is the control response. traction was also observed when the taenia coli was preincubated with papaverine and then washed out with the normal solution (Fig. 2). The effect of papaverine was augmented dose-dependently with increasing its concentration in range from $6 \times 10^{-6} \mathrm{M}$ to $6 \times 10^{-5} \mathrm{M}$. The results are summarized in Tables 1 and 2 .

The contraction of the taenia coli induced by $5 \mathrm{mM}$ caffeine at $12^{\circ} \mathrm{C}$ was slightly smaller than that obtained at $32^{\circ} \mathrm{C}$. When the taenia coli was preincubated with $6 \times 10^{-5}$ $M$ papaverine at $12^{\circ} \mathrm{C}$ and then washed out with the normal solution, papaverine caused no increase, but decreased the caffeine
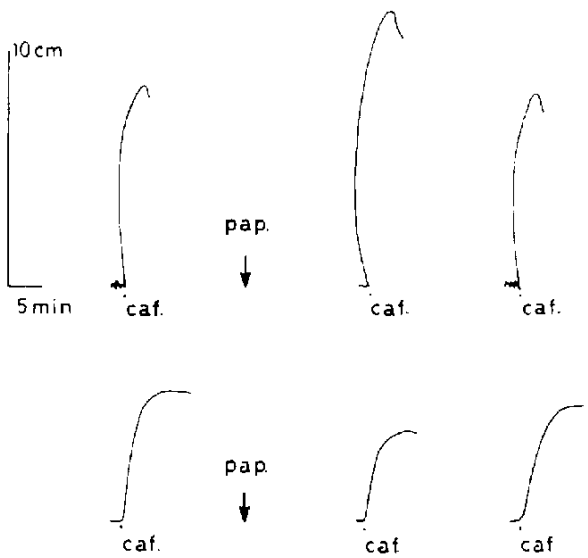

Fig. 2. Responses of the taenia coli to $5 \mathrm{mM}$ caffeine at $32^{\circ} \mathrm{C}$ (upper part) and $12^{\circ} \mathrm{C}$ (lower part). Caffeine was applied every $30 \mathrm{~min}$. At the arrow, the taenia coli was incubated with $6 \times 10^{-5} \mathrm{M}$ papaverine for $10 \mathrm{~min}$ and then washed for $10 \mathrm{~min}$.

Table 1. Caffeirse response of the taenia coli in the presence of papaverine and after removal of papaverine

\begin{tabular}{cccc} 
& \multicolumn{2}{c}{ Contraction \% } \\
& & In the presence & After removal \\
Papaverine $6 \times 10^{-5} \mathrm{M}$ & at $32^{\circ} \mathrm{C}$ & $34.8 \pm 16.7^{* *}$ & $144.3 \pm 11.9^{*}$ \\
& at $12^{\circ} \mathrm{C}$ & $92.9 \pm 5.1$ & $80.6 \pm 2.1^{* *}$ \\
\hline
\end{tabular}

Data are obtained from the experiments presented in Fig. 1. Each value represents the mear: \pm S.E. of 6 experiments. Significant difference *at $P<0.05$ and ** at $P<0.01$ as compared with the contractions obtained before treatment with papaverine. 
Table 2. Caffeine response of the taenia coli after proincubation with papaverine, cyclic AMP. and dibutyryl cyclic AMP

\begin{tabular}{|c|c|c|}
\hline & Contraction $\%$ & $P$ value \\
\hline \multicolumn{3}{|l|}{ At $32^{\circ} \mathrm{C}$} \\
\hline Control & 100 & - \\
\hline \multicolumn{3}{|l|}{ Papaverine } \\
\hline $6 \times 10^{-5} \mathrm{M}$ & $188.4 \pm 21.5$ & $<0.01$ \\
\hline $6 \times 10^{-6} \mathrm{M}$ & $121.0 \pm 6.5$ & $<0.05$ \\
\hline \multicolumn{3}{|l|}{ Papaverine } \\
\hline $\begin{array}{l}6 \times 10^{-6} \mathrm{M}+ \\
\text { cyclic AMP } 10^{-3} \mathrm{M}\end{array}$ & $178.1 \pm 20.5$ & $<0.01$ \\
\hline Cyclic AMP $10^{-3} \mathrm{M}$ & $124.2 \pm 7.5$ & $<0.05$ \\
\hline Dibutyryl cyclic AMP $10^{-4} \mathrm{M}$ & $134.7 \pm 6.2$ & $<0.01$ \\
\hline \multicolumn{3}{|l|}{ At $12^{\circ} \mathrm{C}$} \\
\hline Control & 100 & \\
\hline \multicolumn{3}{|l|}{ Papaverine } \\
\hline $6 \times 10^{-5} \mathrm{M}$ & $81.5 \pm 7.5$ & $<0.05$ \\
\hline
\end{tabular}

Caffeine $(5 \mathrm{mM})$ was applied to the taenia which was preincubated with papaverine, cyclic AMP. and dibutyryl cycilc AMP in the same procedure as shown in Fig. 2. Each value represents the mean \pm S.E. of 6 experiments. Comparisons are macie between values obtained on the same strips in the presence or absence of drugs.

response (Fig. 2). The caffeine contraction induced at $12{ }^{\circ} \mathrm{C}$ in the presence of papaverine was not decreased (Fig. 1). The results are summarized in Tables 1 and 2.

2. Effects of cyclic AMP and dibutyryl cyclic AMP on caffeine response in normal solution: When the taenia coli was preincubated with $3 \times 10^{-4} \mathrm{M}$ cyclic AMP at $32^{\circ} \mathrm{C}$ and then washed out with the normal solution, the caffeine-induced contraction was increased significantly. The degree of increase in the caffeine contraction was smaller than that by papaverine. The concomitant use of $3 \times 10^{-4} \mathrm{M}$ cyclic AMP and $6 \times 10^{-6} \mathrm{M}$ papaverine produced more sig. nificant increase in the caffeine contraction than by single use of papaverine or cyclic AMP. Preincubation with dibutyryl cyclic AMP increased the caffeine-induced contraction, and the degree of the increase was larger than that by cyclic AMP. The results are summarized in Table 2.

3. Effects of papaverine, cyclic AMP, and dibutyryl cyclic AMP on caffeine response in

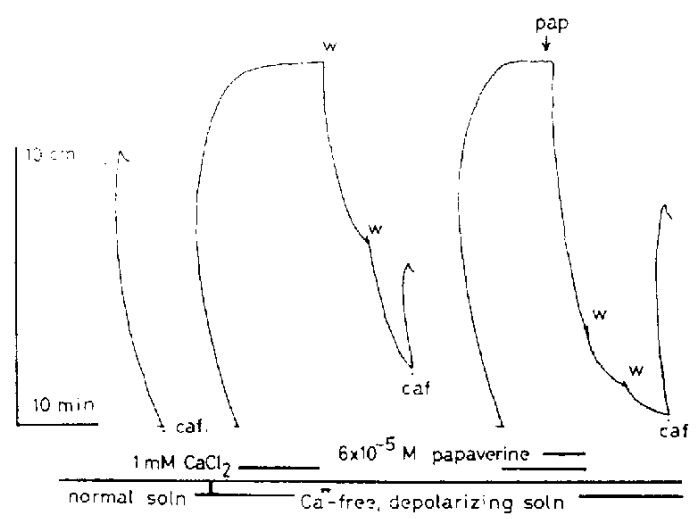

Fig. 3. Responses of the taenia coli to $5 \mathrm{mM}$ caffeine in Ca-free K-solution. The large phasic contraction which developed when the bathing solution was changed from the normal solution to the Ca-free K-solution is not drawn in this figure. The horizontal bars shows the incubation period with $\mathrm{CaCl}_{2}$ or papaverine. At $w$. the muscle was washed twice with the $\mathrm{Ca}$-free K-solution.

Ca-free K-solution: Figure 3 shows the responsiveness of the taenia coli in $\mathrm{Ca}$-free K-solution at $27^{\circ} \mathrm{C}$. When the muscle bathed 
Table 3. Increasing effect of papaverine, cyclic AMP. and dibutyryl cyclic AMP on caffeine contraction induced in Ca-free $K$-solution

\begin{tabular}{ccc}
\hline & Increased \% & Pvalue \\
\hline $\begin{array}{c}\text { Papaverine } \\
6 \times 10^{-5} \mathrm{M}\end{array}$ & $70.0 \pm 12.2$ & 0.01 \\
$6 \times 10^{-6} \mathrm{M}$ & $36.5 \pm 7.6$ & 0.01 \\
Cyclic AMP & & \\
$3 \times 10^{-4} \mathrm{M}$ & $38.8 \pm 11.9$ & 0.05 \\
Dibutyryl cyclic AMP & $62.9 \pm 12.9$ & 0.01 \\
$10^{-4} \mathrm{M}$ & & \\
\hline
\end{tabular}

\footnotetext{
Caffeine $(5 \mathrm{mM})$ was applied to the taenia coli which was treated with drugs during Ca-loading in the same procedure as shown in Fig. 3. Percent increases of the contractions were estimated by comparison with those of paired strips induced after treatment with or without drugs. Each value represents the mean \pm S.E. of 6 experiments. As compared with the coresponding controls, significant differences are observed in all cases.
}

in normal solution was exposed to the $\mathrm{Ca}$-free K-solution, a large phasic contraction took place: but the muscle tone returned to the initial level during washing with the Ca-free K-solution. Application of $5 \mathrm{mM}$ caffeine after the return of the muscle tone evoked a contraction of the taenia coli. However, the taenia coli no longer responded to caffeine applied after the muscle had been washed out with the Ca-free K-solution. The responsiveness of the taenia coli to caffeine was restored by loading the muscle with $1 \mathrm{mM}$ $\mathrm{CaCl}_{2}$ for $10 \mathrm{~min}$. Although a large contraction occured during the $\mathrm{Ca}$-loading, it promptly returned to the basal level by washing with the $\mathrm{Ca}$-free K-solution. When papaverine was applied to the muscle for the latter $5 \mathrm{~min}$ of the $10 \mathrm{~min} \mathrm{Ca}$-treatment period, the $\mathrm{CaCl}_{2}$-induced contraction was abolished; but the contractile response of the taenia coli induced by application of caffeine after the $\mathrm{Ca}$-loading treatment was enhanced by the presence of papaverine. This enhancing effect of papaverine was dose-dependent in the concentration range from $6 \times 10^{-6} \mathrm{M}$ to $6 \times 10^{-5} \mathrm{M}$ (Table 3). Cyclic AMP $\left(3 \times 10^{-4} \mathrm{M}\right)$ and dibutyryl cyclic AMP $\left(10^{-4} \mathrm{M}\right)$ also increased the caffeine contraction induced in the Ca-free K-solution when they were applied to the taenia coli instead of papa-

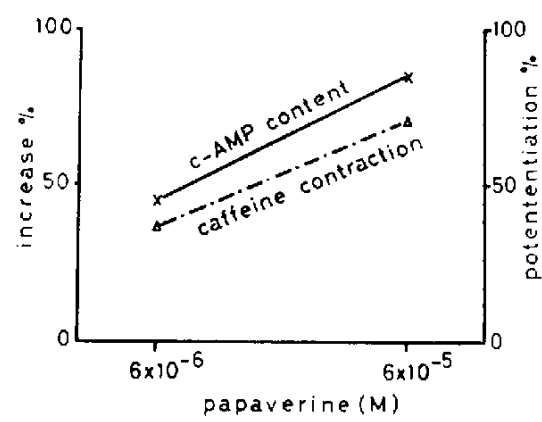

Fig. 4. Correlation between effects of papaverine on caffeine response and on the tissue cyclic AMP level. Data were obtained from 6 to 12 experiments. Data of the potentiating effect of papaverine on caffeine contraction were also shown in Table 3. Papaverine at $6 \times 10^{-6} \mathrm{M}$ and $6 \times 10^{-5} \mathrm{M}$ increased the tissue cyclic AMP level by $44.4 \%$ and $87.0 \%$, respectively.

verine during the Ca-loading process. As shown in Table 3, the effect of dibutyryl cyclic AMP was significantly larger than that of cyclic AMP.

4. Effects of papaverine on tissue cyclic AMP level: Figure 4 shows the effect of papaverine on the tissue cyclic AMP content of the taenia coli. The tissue cyclic AMP content was examined in the muscle treated with $1 \mathrm{mM} \mathrm{CaCl}_{2}$ in the presence or absence of papaverine as described in Fig. 3. The level of the control tissue was $0.54 \pm 0.05$ pmole cyclic AMP/mg wet tissue. Papaverine 
increased dose-dependently the tissue cyclic AMP level in the concentration range from $6 \times 10^{-6} \mathrm{M}$ to $6 \times 10^{-5} \mathrm{M}$.

Figure 4 also represents the relationship between the effects of papaverine on the caffeine response and on the tissue cyclic AMP level. A good correlation was observed between the papaverine-induced increase of caffeine response and of the cyclic AMP level.

\section{DISCUSSION}

It is well recognized that the contraction of smooth muscle is initiated by calcium ion supplied to the contractile protein in the same manner as in skeletal muscle (6). However, the sources of calcium ion supplied are different in both muscles, that is, sarcoplasmic reticulum is the only source for the calcium ion in skeletal muscle (6), but both intracellular and extracellular calcium sources have been proposed to contribute to smooth muscle contraction (10). Although caffeine is well known to induce contraction by releasing calcium from the sarcoplasmic reticulum in skeletal muscle. in the case of smooth muscle, which source of calcium is utilized on caffeine-induced contraction has not been identified. In our preliminary work. it was found that the caffeine-induced contraction of guinea-pig taenia coli was scarcely depressed by D-600, a well-known calcium antagonist, but high potassium-induced contraction was markedly reduced by D-600; and it was observed that caffeine evoked a contraction of the muscle even in Ca-free. depolarizing solution (unpublished data). From these findings, we suggest that caffeine may induce the contraction of the taenia coli mainly by releasing calcium ion from intracellular storage sites. Endo and his coworkers $(7,8)$ also claimed that the contraction of the taenia coli induced by caffeine may be due to a release of calcium ion from some storage sites, and this was based on observations that caffeine could elicit contractions in the muscle suspended in $\mathrm{Ca}$-free. depolarizing solution and in the chemically skinned muscle fiber.

Since the amplitude of the muscle contraction should be proportionally related to the concentration of free calcium ion in the cytoplasm (8). determination of the change in the amplitude of the muscle contraction will make it possible to estimate a relative change in the concentration of cytoplasmic calcium ion. Therefore, an increase in the amplitude of the contraction induced by caffeine may represent an increase in the quantity of intracellularly stored calcium which is mobilized by caffeine.

In the present work, the caffeine-induced contraction was shown to be enhanced when the taenia coli was treated with papaverine (Tables 1, 2, and 3). This fact suggests that papaverine may stimulate an accumulation of cytoplasmic calcium ion to its storage sites and increase the quantity of calcium ion released intracellularly by caffeine. If this is the case, papaverine must cause relaxation of the smooth muscle prior to increment of caffeine contraction since the enhanced calcium accumulation could produce a decrease in cytoplasmic calcium ion level. In fact, the caffeine-induced contraction of the taenia coli was inhibited in the presence of papaverine, but enhanced after removing papaverine by washing the muscle as shown in Fig. 2 and Table 2. Furthermore, when papaverine was applied to the taenia coli during the Ca-loading. papaverine caused relaxation of the muscle contracted by $\mathrm{CaCl}_{2}$; and after the removal of papaverine by washing the muscle, the caffeine-induced contraction was enhanced as compared to that obtained in the muscle loaded with calcium in the absence of papaverine (Fig. 3 and Table 3). Bolton (11) also asserted that binding or sequestration of calcium ion into intracellular storage sites 
could be important not only for terminating contraction, but also because such bound calcium may be available for subsequent contraction.

The accumulation of cytoplasmic calcium to intracellular storage sites is presumed to couple with an energy dependent process (12). Therefore the calcium accumulation is expected to be depressed at a low temperature such as $12^{\circ} \mathrm{C}$. In fact, when the bathing temperature was lowered to $12^{\circ} \mathrm{C}$, the effect of papaverine on the caffeine contraction of the muscle was abolished. As shown in Figs. 1 and 2, the caffeine contraction of the muscle was not decreased in the presence of papaverine at $12^{\circ} \mathrm{C}$; and in addition, the caffeine contraction was not enhanced but rather decreased after preincubation with papaverine. These findings suggest that the increasing effect of papaverine on caffeine response may be related to its action on a temperature sensitive calcium accumulation process. Hurwitz et al. (12) reported that ATP dependent calcium binding in the microsomal fraction is markedly inhibited when the incubation temperature was lowered from $32^{\circ} \mathrm{C}$ to $10^{\circ} \mathrm{C}$.

Several workers obtained evidence suggesting that an increase in the cyclic AMP level of smooth muscle cells leads to the muscle relaxation (13-15). It is well known that papaverine increases intracellular cyclic AMP level by inhibiting the phosphodiesterase which hydrolyzes cyclic AMP (16). Recent studies have revealed the existence of a good correlation between papaverineinduced smooth muscle relaxation and intracellular cyclic AMP increase (17-20). It was also reported that dibutyryl cyclic AMP mimicks the effects of papaverine on the electrical and mechanical responses of smooth muscle (21). In the present experments, it was shown that cyclic AMP and its dibutyryl derivative produced similar effects as those of papaverine on the caffeine-induced con- traction (Tables 2 and 3 ) and that a combind use of cyclic AMP and papaverine induced a much larger effect as compared with that by papaverine alone (Table 2). Furthermore, a good correlation was observed between the papaverine-induced increases of caffeine response and of the cyclic AMP level (Fig. 4). These findings strongly suggest that the enhancing effect of papaverine on caffeine response may be closely related to the increase in intracellular cyclic AMP level. Casteels and Raeymaekers (22) found that isoprenaline augmented the carbachol response elicited in Ca-free medium when the drug was applied to the taenia coli during Ca-loading. On the basis of this finding, they suggested that the augmentation of the carbachol response may result from an increase in the amount of intracellularly stored calcium; and the increased uptake of calcium ion into the storage sites may lead to the smooth muscle relaxation. Although they did not mention about the mechanism of the isoprenaline action, it is probable that the uptake of calcium ion may be caused by a similar mechanism to that of papaverine since the activation of $\beta$-adrenoceptors by isoprenaline also results in elevation of cytoplasmic cyclic AMP level. Therefore, the finding of Casteels and Raeymaekers may also support our concept that the increase in cellular cyclic AMP accelerates the sequestration of calcium ion.

Marshall and Kroeger (19) and Inatomi et al. (20) demonstrated that the smooth muscle relaxation induced by papaverine was preceded by an increase in intracellular cyclic AMP level. Furthermore, cyclic AMP has been found to stimulate calcium accumulation of microsomal fractions obtained from various smooth muscles $(1,12)$. Therefore, it is considered that papaverine first increases cyclic AMP level of the taenia coli and the increased cyclic AMP then stimulates sequestration of calcium ion into its storage 
sites, finally leading to smooth muscle relaxation.

Tomivama et al. (4) demonstrated that papaverine and dibutyryl cyclic AMP stimulated $\mathrm{Ca}$-efflux of guinea-pig taenia coli, suggesting that papaverine induced smooth muscle relaxation through acceleration of Ca-efflux which might be mediated by cyclic AMP. More recently, Takayanagi et al. (5) reported that papaverine relaxes the depolarized taenia caecum of the guinea pig through a cyclic AMP independent mechanism which inhibits tissue uptake of extracellular calcium ion. Generalizing from the above described facts, papaverine is likely to induce smooth muscle relaxation through its combined actions such as stimulation of calcium sequestration, acceleration of Ca-efflux, and inhibition of Ca-influx.

\section{REFERENCES}

1) Andersson, R.: Cyclic AMP and calcium ions in mechanical and metabolic responses of smooth muscles: influence of some hormones and drugs. Acta Physiol. Scand. Supp. 382, 1-59 (1972)

2) Takayanagi, I., Yamashita, H., Manda, T. and Takagi, K: Calcium ions and relaxation of intestinal smooth muscle induced by papaverine and Aspaminol. Japan. J. Pharmacol. 27, 311314 (1977)

3) Takayanagi, 1., Hisayama, T. and Suzuki, S. Effects of nonspecific smooth muscle relaxants and Ca-blocker on Ca-release and $\mathrm{Ca}$-binding in microsomal fractions from rabbit taenia coli. Japan. J. Pharmacol. 30, 641-646 (1980)

4) Tomiyama, A., Takayanagi, I. and Takagi, K.: Relaxation of intestinal smooth muscle and calcium movements. J. Pharm. Pharmacol. 25, 65-68 (1973)

5) Takayanagi, I., Karasawa, A. and Kasuya, Y.: Relaxation of depolarized guinea pig taenia caecum inauced by some antispasmodics. Europ. J. Pharmacol. 50, 137-143 (1978)

6) Ebashi, S. and Endo, M.: Calcium ions and muscle contraction. Progr. Biophys. Mol. Biol. 18, 123-183 (1968)

7) Endo, M., Kitazawa, T. and Yagi, S.: Different features of responses of the sarcoplasmic reticulum in cardiac and smooth muscle. In Muscle Contraction: Its Regulatory Mecha- nisms, Edited by Ebashi, S., Murayama, K. and Endo, M., p. 447-463, Japan. Sci. Soc. Press. Tokyo (1980)

8) Endo, M., Kitazawa, T., Yagi, S., lino, M. and Kakuta, Y.: Some properties of chemically skinned smooth muscle fiber. In ExcitationContraction Coupling in Smooth Muscle, Edited by Casteels. R., Godfraind, T. and Rüegg. J.C., p. 199-209. Elsevier/NorthHolland Biomedica! Fress (1977)

9) Gilman, A.G.: A protein binding assay for adenosine $3^{\prime}, 5^{\prime}$-cyclic monophosphate. Proc. natn. Acad. Sci. U.S.A. 69, 305-312 (1970)

10) Hurwitz, L. and McGuffee, L.J.: Calcium in smooth muscle function. In Catcium in Drug Action, Edited by Weiss, G.B., p. 75-93. Plenum Press. Now York (1978)

11) Bolton, T.B.: Mechanisms of action of transmitters and other substances on smooth muscle. Physiol. Rev. 59, 606-718 (1979)

12) Hurwitz, L., Debbas, G. and Little, S.: Effects of temperature and inorganic ions on caicium uptake in microsomes. In Biachemistry of Smooth Muscle, Edited by Stephens, N.L., p. 595-615. University Park Press, Baltimore (1977)

13) Robison, G.A., Butcher, R.W. and Sutherland, E.W.: Cyclic AMP. Academic Press, New York (1971)

14) Triner, L., Nahans, G.G., Vulliemoz, Y., Overweg, N.I.A., Verosky, M., Habif, D.V. and Ngai, S.H.: Cyclic AMP and smooth muscle function. Ann. N.Y. Acad. Sci. 185, 458-476 (1971)

15) Bär, H.P.: Cyclic nucleotides and smooth muscle. Adv. Cyclic Nucleotide Res. 4, 195237 (1974)

16) Pöch, G. and Kukovetz, W.R.: Papaverineinduced inhibition of phosphodiesterase activity in various mammalian tissues. Life Sci. 10, 133-144(1971)

17) Uruno, T., Takayanagi, I., Kubota, K. and Takagi, K.: Comparison of action of papaverine, Aspaminol and isoprenaline on isolated rat uterus. Japan. J. Pinarmacol. 24, 219-226 (1974)

18) Inatomi, N., Takayanagi, I, and Takagi, K.: Antiphosphodiesterase activity and nonspecific smocth muscle relaxation tested on intestinal smooth muscle. Japan. J. Pharmacol. 25, 6369 (1975)

19) Marshall, J.E. and Kroeger, E.A.: Adrenergic influences on uterine smooth muscle. Phil. Trans. R. Soc. B 265, 135-148 (1973)

20) Inatomi, N., Takayanagi, I., Uchida, M. and Takagi, K.: Intracellular cyclic AMP level and intestinal smooth muscle relaxation. Europ, J. 
Pharmacol. 26, 73-76 (1974)

21) Takagi, K., Takayanagi, I. and Tomiyama, A.: Actions of dibutyryl cyclic adenosine monophosphate, papaverine and isoprenaline on intestinal smooth muscle. Japan. J. Pharmacol. $21,477-483$ (1971)
22) Casteels, R. and Raeymaekers, L.: The action of acetylcholine and catecholamines on an intracellular calcium store in the smooth muscle cells of the guinea-pig taenia coli. J. Physiol. 294, 51-68 (1979) 